\title{
ERRATUM
}

\section{Relational victimization, friendship, and adolescents' hypothalamic-pituitary-adrenal axis responses to an in vivo social stressor-ERRATUM}

\author{
CASEY D. CALHOUN,${ }^{a}$ SARAH W. HELMS,${ }^{a}$ NICOLE HEILBRON,${ }^{b}$ KAREN D. RUDOLPH,${ }^{c}$ \\ PAUL D. HASTINGS, ${ }^{d}$ AND MITCHELL J. PRINSTEIN ${ }^{a}$ \\ ${ }^{a}$ University of North Carolina at Chapel Hill; ${ }^{b}$ Duke University; ${ }^{c}$ University of Illinois, Urbana-Champaign; and ${ }^{d}$ University of \\ California, Davis
}

doi:10.1017/S0954579414000261, published by Cambridge University Press, 22 July 2014

The solid and dotted lines in the High Positive Friendship Quality section of Figure 4 were reversed in the original arti-

\section{Reference}

Calhoun, C. D., Helms, S. W., Heilbron, N., Rudolph, K. D., Hastings, P. D., \& Prinstein, M. J. (2014). Relational victimization, friendship, and ado- cle. The corrected figure is reprinted herein. We regret this error and any problems it may have caused.

Address correspondence and reprint requests to: Casey Calhoun, Department of Psychology, University of North Carolina at Chapel Hill, Davie Hall, CB 3270, Chapel Hill, NC 27599-3270; E-mail: cdcalhou@email.unc.edu; or Mitch Prinstein, Department of Psychology, University of North Carolina at Chapel Hill, Davie Hall, CB 3270, Chapel Hill, NC 27599-3270; E-mail: mitch.prinstein@unc.edu. cial stressor. Development and Psychopathology, 26, 605-618. 


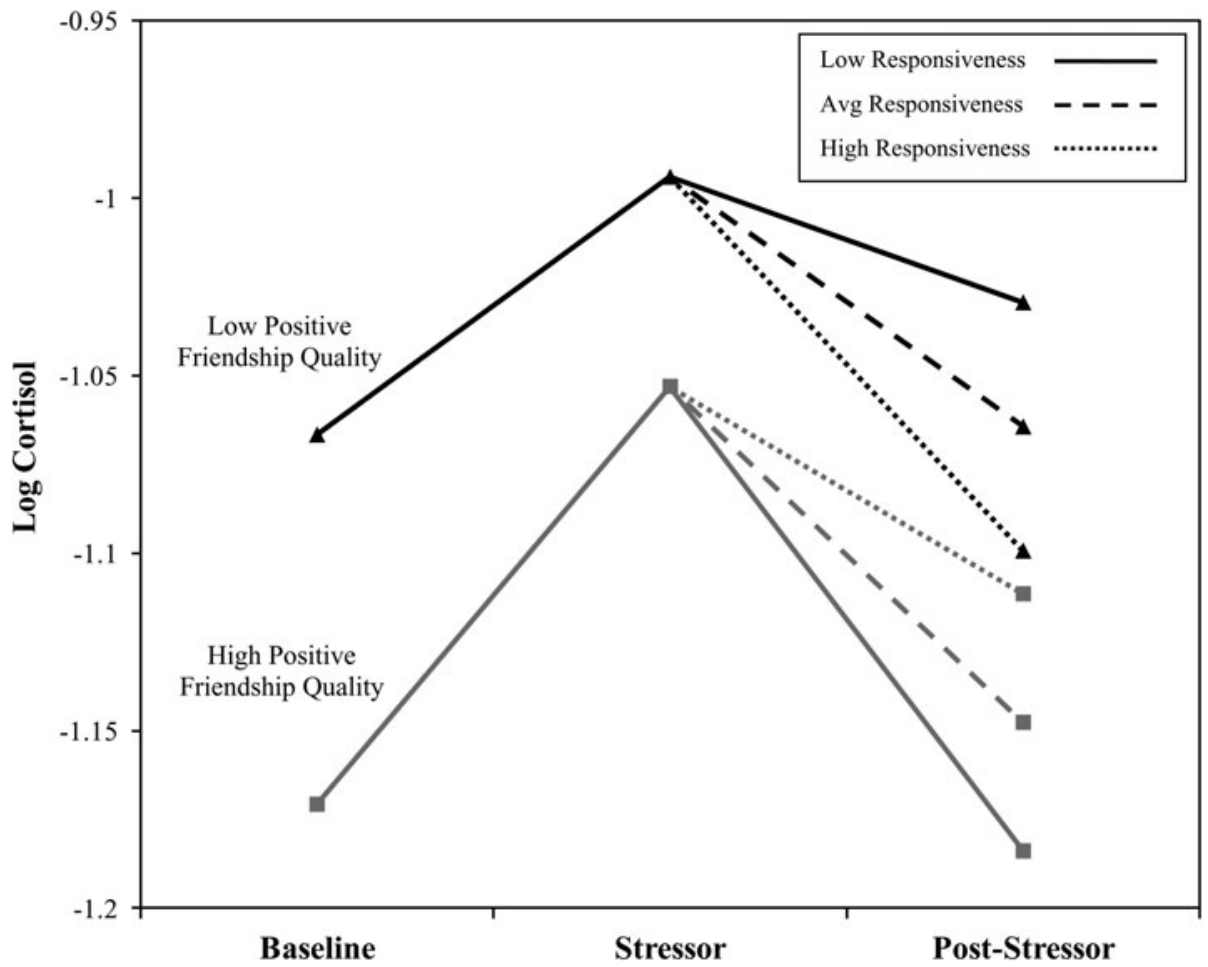

Figure 4. Linear functions showing different degrees of cortisol recovery by level of positive friendship quality and observed responsiveness $($ average $=$ mean; high/low $=$ mean $\pm 1 S D$ ). 